\title{
Color improves speed of processing but not perception in a motion illusion
}

\author{
Carolyn J. Perry ${ }^{1,2}$ and Mazyar Fallah ${ }^{1,2,3}$ * \\ ${ }^{1}$ Visual Perception and Attention Laboratory, School of Kinesiology and Health Science, York University, Toronto, ON, Canada \\ ${ }^{2}$ Centre for Vision Research, York University, Toronto, ON, Canada \\ ${ }^{3}$ Canadian Action and Perception Network, York University, Toronto, ON, Canada
}

\section{Edited by:}

Jeroen J. A. Van Boxtel, University of California Los Angeles, USA

Reviewed by:

Eric Hiris, St. Mary's College of

Maryland, USA

Kiley Seymour, Charité, Germany

${ }^{*}$ Correspondence:

Mazyar Fallah, School of Kinesiology and Health Science, York University, 4700 Keele Street, Toronto, ON,

Canada M3J 1P3.

e-mail:mfallah@yorku.ca
When two superimposed surfaces of dots move in different directions, the perceived directions are shifted away from each other. This perceptual illusion has been termed direction repulsion and is thought to be due to mutual inhibition between the representations of the two directions. It has further been shown that a speed difference between the two surfaces attenuates direction repulsion. As speed and direction are both necessary components of representing motion, the reduction in direction repulsion can be attributed to the additional motion information strengthening the representations of the two directions and thus reducing the mutual inhibition. We tested whether bottom-up attention and topdown task demands, in the form of color differences between the two surfaces, would also enhance motion processing, reducing direction repulsion. We found that the addition of color differences did not improve direction discrimination and reduce direction repulsion. However, we did find that adding a color difference improved performance on the task. We hypothesized that the performance differences were due to the limited presentation time of the stimuli. We tested this in a follow-up experiment where we varied the time of presentation to determine the duration needed to successfully perform the task with and without the color difference. As we expected, color segmentation reduced the amount of time needed to process and encode both directions of motion. Thus we find a dissociation between the effects of attention on the speed of processing and conscious perception of direction. We propose four potential mechanisms wherein color speeds figure-ground segmentation of an object, attentional switching between objects, direction discrimination and/or the accumulation of motion information for decision-making, without affecting conscious perception of the direction. Potential neural bases are also explored.

Keywords: attention, consciousness, awareness, color, motion, vision, illusion, perception

\section{INTRODUCTION}

In the study of attention and consciousness it is important to operationally define the terms as there are multiple definitions in the literature. We define attention as the preferential processing of a subset of visual information selected either by bottomup (stimulus-driven) features or through goal-driven top-down processes. Top-down or goal-driven attention is dependent on task demands which require attending to a location, feature, or object, and is dependent on fronto-parietal networks (Corbetta et al., 1993; Nobre et al., 1997; Corbetta, 1998; Shulman et al., 1999; Yantis and Serences, 2003; Serences et al., 2004; Kelley et al., 2008; Ozaki, 2011) that modulate visual processing areas. Attentional selection by bottom-up or stimulus-driven factors has also been called pre-attentive processing or early (versus late) selection. All three nomenclatures describe feature differences that are rapidly and easily processed, such as differences in contrast, hue, orientation, form, or motion. Bottom-up attention is thought to give rise to a map of attentional priority for each object in the field of view, either as a master salience map (Treisman and Gelade, 1980; Koch and Ullman, 1985; Neibur and Koch, 1996; Itti and
Koch, 2001; Thompson and Bichot, 2005) or at individual stages of visual processing (e.g., Selective Tuning Model of attention, Tsotsos et al., 1995). Bottom-up and top-down mechanisms work together in driving attentional selection. The effects of attention are often measured as either speeded processing which produces faster reaction times in detection tasks (e.g., Posner, 1980) or as improved visual sensitivity producing lower perceptual thresholds (Mueller and Humphreys, 1991), smaller just-noticeable differences in feature processing (Nakayama and Mackeben, 1989), or better signal-to-noise discrimination (Dosher and Lu, 2000).

Consciousness is the internal awareness, from near-threshold awareness (Marks and Stevens, 1968; Azzopardi and Cowey, 1997; Kunimoto et al., 2001) to full conscious experience, of visual input, which is different than unconscious visual processing (as in blindsight, Weiskrantz, 1986; Azzopardi and Cowey, 1997, 1998; Stoerig and Cowey, 1997). This definition is supported by studies that quantify the strength of the conscious experience through confidence ratings (Kolb and Braun, 1995; Kunimoto et al., 2001; Boyer et al., 2005; Wilimzig et al., 2008). Conscious awareness occurs when a stimulus reaches a threshold and can then be focused upon 
or queried. At that stage, the features of the object can be processed and bound into the object. It has been shown that different features take differing amounts of time to be processed and reach awareness: orientation is processed faster than color (e.g., Bodelon et al., 2007) and color is processed faster than motion (Moutoussis and Zeki, 1997). As each feature is processed, that feature of the object reaches consciousness. Therefore being conscious of an object is not a unitary experience: you can be conscious of different features of the same object at different times (Dennett and Kinsbourne, 1992; Noe and O'Regan, 2002). Conscious awareness of an object does not wait for the slowest feature of that object to be processed (Bodelon et al., 2007). Thus there are two parts of consciousness that can be queried: awareness of the stimulus existing and the conscious perception of the feature. Much of our conscious perception is driven by visual processing as evidenced in a myriad of visual illusions such as the waterfall illusion (Anstis et al., 1998), moon illusion (Kaufman and Rock, 1962), McCollough effect (McCollough, 1965), Land effect (Land and McCann, 1971), and Titchener circles (Pavani et al., 1999). These visual elements not only reach conscious awareness, but are also consciously perceived as being different than the veridical visual input. In multi-object tracking (MOT), target objects can be tracked as they move amongst distractors but the features and identity of the objects are not well processed (Scholl and Pylyshyn, 1999; Bahrami, 2003; Pylyshyn, 2004). Thus, conscious awareness of an object and perception of its features can be dissociated from each other.

We can relate consciousness to the attentional literature: a simple detection task queries awareness whereas a discrimination task queries perception. A number of paradigms including attentional blink (Broadbent and Broadbent, 1987; Raymond et al., 1992), change blindness (Rensink et al., 1997), inattentional blindness (Rock et al., 1992), load-induced blindness (Lavie, 1995), and visual neglect (Driver and Mattingley, 1998) have shown an apparent failure of conscious awareness in the absence of attention (for review see van Boxtel et al., 2010a). Attention also affects objects that easily reach awareness: attentional effects on detection tasks are often measured by speed of response, i.e., reaction time (e.g., spatial cueing paradigm: Posner, 1980). Other studies have suggested that attention does not affect conscious awareness directly, but instead affects the sensitivity of the visual system. The presence of spatial attention improves contrast sensitivity (Lee et al., 1999a; Carrasco et al., 2000; Reynolds et al., 2000; Di Russo et al., 2001; Moore and Fallah, 2001, 2003, 2004). The absence of attention results in a decrease in discrimination of luminance and color contrasts, orientation, and spatial frequency (Lee et al., 1999b; Morrone et al., 2002, 2004). Furthermore, spatial attention and increased contrast have similar effects on neuronal firing (Mangun et al., 1998; Boynton et al., 1999; Reynolds and Desimone, 2003). However, it should be noted that the effects of attention on visual sensitivity and neuronal responses only occur when there are multiple stimuli to be simultaneously processed (Spitzer et al., 1988; Desimone and Duncan, 1995; McAdams and Maunsell, 2000; Martinez-Trujillo and Treue, 2004; Reynolds and Fallah, 2004; Fallah et al., 2007; Sundberg et al., 2009) and attention has little effect on single stimuli (Luck et al., 1997; Moore and Fallah, 2004; Tsuchiya and Braun, 2007). While these studies suggest that attention and consciousness can be dissociated, it is still in contention which attentional mechanisms give rise to awareness and which affect perception.

Perceptual illusions have an advantage in the study of consciousness in that the conscious percept is dissociated from the physical stimulus and is instead created by neural processing (de Gardelle et al., 2009, 2010). Instead of using post hoc confidence ratings, the strength of the illusion can be used to measure consciousness. For example, prior research has used the strength of the afterimages (Suzuki and Grabowecky, 2003; Hofstoetter et al., 2004; van Boxtel et al., 2010b) to study the relationship between attention and consciousness, Similarly, that relationship is also studied with motion illusions (motion aftereffect: van de Grind et al., 2001; Castelo-Branco et al., 2009; Kaunitz et al., 2011; Murd and Bachmann, 2011; motion-induced mislocalization: Tse et al., 2011). We used a different perceptual motion illusion, direction repulsion (Marshak and Sekuler, 1979), to investigate the relationship between attention and consciousness. In this illusion, observers perceive the directions of motion of two superimposed surfaces as being repulsed away from each other. The conscious experience of this event is a misrepresentation of the actual motion directions, and occurs with superimposed random dot kinetograms (Marshak and Sekuler, 1979; Mather and Moulden, 1980; Hiris and Blake, 1996; Braddick et al., 2002; Curran and Benton, 2003) or superimposed gratings (Kim and Wilson, 1996). The illusion is strong, producing a percept that is repulsed up to $20^{\circ}$ away from the real direction of each surface (Marshak and Sekuler, 1979; Braddick et al., 2002). While the direction of a sole surface is accurately perceived, the superimposition of two surfaces is thought to produce a competition between the representations of the two directions, a process termed mutual inhibition which results in repulsion (Marshak and Sekuler, 1979; Mather and Moulden, 1980). As stated previously, the effects of attention on visual sensitivity are generally seen with multiple stimuli as single stimuli are processed with full resources. Similarly, the competition between the two surfaces' directions interferes with their processing (Braddick et al., 2002) producing the repulsion. In the standard direction repulsion illusion, all features of the surfaces are identical except for the direction. So the ability to select one of the surfaces is based solely on the direction information which is what produces the repulsion. Additional feature differences between the surfaces would provide other handles by which to select a surface. So attentional mechanisms should reduce the interference between the two directions and attenuate the repulsion, resulting in a more veridical percept. A reduction in repulsion does in fact occur due to bottom-up saliency produced by differences in speed (Marshak and Sekuler, 1979; Curran and Benton, 2003) or spatial frequency (Kim and Wilson, 1996). When the surfaces are distinguished by speed or spatial frequency differences, selection can work through those features to reduce the illusion. However, a real depth difference produced by stereoscopic viewing does not attenuate direction repulsion (Hiris and Blake, 1996). When the two surfaces are in the same depth plane, they are already perceived to be in different apparent depth planes (Hiris and Blake, 1996). Therefore, the addition of stereoscopic depth does not add additional features to select by. 
Speed and spatial frequency, as well as direction and depth, are all components of motion processing in the dorsal stream (Maunsell and Van Essen, 1983a,b; Albright, 1984; Mikami et al., 1986a,b; Van Essen and Gallant, 1994; Bradley and Andersen, 1998; DeAngelis and Newsome, 1999). Thus this bottom-up attentional effect could be limited to concurrently processed motion features processed by local circuitry within motion areas. Since reporting a second feature on the same object has been shown to not require additional resources (Duncan, 1984), we asked whether the addition of a motion-irrelevant feature processed in the ventral stream, such as color, could also attenuate direction repulsion. A salient color difference allows for selection of the objects, not just the concurrently processed motion information. Thus, we tested whether bottom-up attention (in the form of color segmentation) reduces direction repulsion in local motion circuits or at the level of binding color to motion. In the unicolor condition, participants reported the two directions of motion (similar to the procedure in Braddick et al., 2002, Experiment 2). In the color-segmented condition, participants reported the combination of color and direction, thus also activating top-down mechanisms involved in selecting objects by color. We tested whether bottom-up segmentation and top-down task demands involving one feature of an object would affect the conscious perception of other features of the object.

Both the unicolor and color-segmented conditions required top-down attention to the direction of the objects. We activated bottom-up attentional mechanisms by the use of color segmentation cues and also added the top-down attentional demand of linking each direction to the color of the surface. Note that bottomup attention is not as often studied with regard to consciousness as it requires comparison between conditions that have different physical stimulus properties, whereas top-down attention can be allocated differently to the same visual scene, either as spatial (Jonides, 1981; Egeth and Yantis, 1997; Driver, 2001; RodriguezSanchez et al., 2007; Tsotsos, 2011), feature-based (Treue and Martinez-Trujillo, 1999; Saenz et al., 2002; Tsotsos, 2011), or object-based attention (Valdes-Sosa et al., 1998, 2000; O'Craven et al., 1999; Fallah et al., 2007). Bottom-up attention is therefore expected to be linked with conscious perception, which is likely why the addition of speed or spatial frequency differences attenuate direction repulsion (Marshak and Sekuler, 1979; Kim and Wilson, 1996; Curran and Benton, 2003). Furthermore the ventral stream which processes color has the function of processing vision for perception, i.e., consciousness (Goodale and Milner, 1992; Milner and Goodale, 1993). For these reasons, we expected that the addition of color segmentation cues would also attenuate direction repulsion. Surprisingly, we found that the addition of color differences did not affect direction repulsion. While not affecting the conscious perception of surface direction, this attentional cueing did in fact have an effect on visual processing: color decreased the time needed to process both directions of motion. While speeded reaction time is a well-studied effect of visual attention (Posner, 1980; Jonides, 1981; Driver, 2001, for review see Egeth and Yantis, 1997), here we have shown that speeded visual processing can be dissociated from the perceptual outcome of that processing. Finally, we relate these findings to possible underlying mechanisms and attentional networks.

\section{MATERIALS AND METHODS PARTICIPANTS}

In Experiment 1, six participants (ages 21-47, two female) completed the unicolor: white paradigm, six participants (age 18-31, one female) completed the unicolor: red or green paradigm, and six participants (ages 20-26, two female) completed the colorsegmented paradigm. In Experiment 2, an additional 24 naïve individuals participated: 12 in the unicolor paradigm (ages 18-27, three female) and 12 in the color-segmented paradigm (ages 1926, 10 female). All participants had normal or corrected-to-normal visual acuity, and none tested positive for color blindness using Ishihara plates. The research was approved by York University's Human Research Participation Committee. Informed consent was obtained from all participants.

\section{PROCEDURE}

Participants sat in a darkened, quiet room, $57 \mathrm{~cm}$ away from a computer monitor $\left(21^{\prime \prime}\right.$ ViewSonic, $1280 \times 1024$ resolution, $60 \mathrm{~Hz}$ ) with their head position stabilized by a headrest (Headspot, UHCOtech). They wore a head-mounted, infrared eye tracker (Eyelink II, SR Research Ltd., $500 \mathrm{~Hz}$ ) monitoring right eye position. Stimuli were created using Matlab (The Mathworks Corp.). Experimental control was maintained by Presentation (Neurobehavioral Systems). Data was analyzed using Matlab and SPSS (SPSS Inc.).

Participants fixated a white cross centered on a black screen (see Figure 1). After $200 \mathrm{~ms}$, a circular aperture appeared in the lower right quadrant. The aperture consisted of two superimposed, $100 \%$ coherent random dot kinetograms (RDKs: dot size $=0.04^{\circ}$, aperture size $=5^{\circ}$, dot density $=1.54$ dots $/$ degree $^{2}$, velocity $=3^{\circ} / \mathrm{s}$ ) moving in two different directions. We tested all combinations of one direction drawn from the vertical axis $\left( \pm 2^{\circ}, 6^{\circ}\right.$, and $10^{\circ}$ from either up or down) and the other from the horizontal axis $\left( \pm 2^{\circ}\right.$, $6^{\circ}$, and $10^{\circ}$ from either left or right). While all directions appeared with equal frequency, this created differences between the two directions that ranged from $70^{\circ}$ to $110^{\circ}$. If fixation was broken the trial was aborted and randomly reinserted into the remaining trials. After a period of time (Experiment 1: $1000 \mathrm{~ms}$, Experiment 2: variable, see below), the aperture was replaced with a circular outline (response circle) on which the participants indicated the directions of motion of each surface by mouse clicks. In the unicolor: white paradigm, both surfaces were white $\left(24.4 \mathrm{~cd} / \mathrm{m}^{2}\right)$ as was the response circle. In the unicolor: red or green paradigm, both surfaces were either red or green (red: $x=11.97$, $y=24.37$; green: $x=46.37, y=24.38$; isoluminant, $24.4 \mathrm{~cd} / \mathrm{m}^{2}$ ), pseudorandomly interleaved. In the color-segmented paradigm, one surface was red and the other was green (red: $x=11.97$, $y=24.37$; green: $x=46.37, y=24.38$; isoluminant, $24.4 \mathrm{~cd} / \mathrm{m}^{2}$ ). Participants responded on sequential colored circles whose order was randomly interleaved across trials.

In Experiment 1, the unicolor: white paradigm resulted in a 12 (Surface 1 Direction) $\times 12$ (Surface 2 Direction) experimental design. The unicolor: red or green paradigm resulted in a 12 (Surface 1 Direction $) \times 12$ (Surface 2 Direction $) \times 2$ (Surface Color $)$ design. The color-segmented paradigm resulted in a 12 (Surface 1 Direction $) \times 12($ Surface 2 Direction $) \times 2($ Surface Color $) \times 2$ 


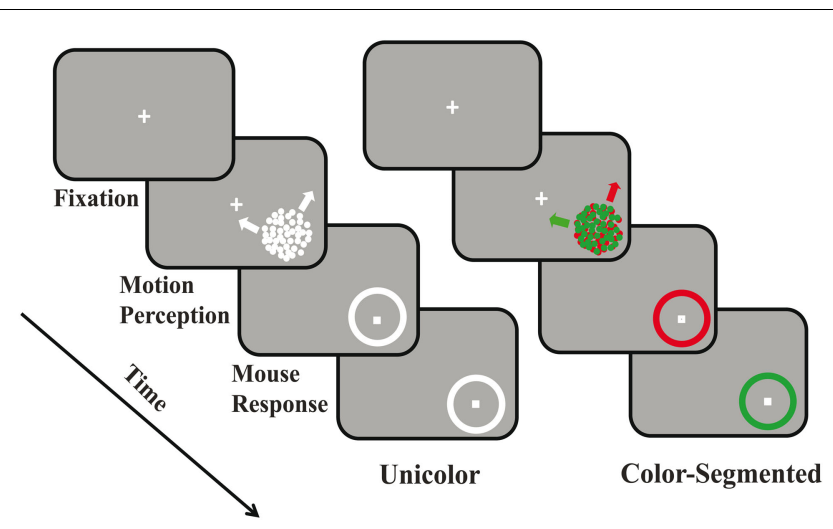

FIGURE 1 | Experimental paradigm. In both the unicolor and color-segmented conditions participants initially fixated a central white " +." After fixation was maintained for $200 \mathrm{~ms}$ an aperture containing two superimposed, coherently moving random dot kinetograms, appeared in the lower right quadrant. In Experiment 1, stimulus duration was set at $1000 \mathrm{~ms}$ while in Experiment 2, stimulus duration was varied. Participants were to remain fixated during stimulus presentation. A response circle replaced the surfaces, and participants were then free to move their eyes. In the unicolor condition participants made two mouse clicks on the same white response circle indicating the perceived directions of motion. In the color-segmented condition, there were two response circles, one appearing after the other (randomly interleaved). Participants clicked once on each to indicate the perceived direction of motion of that colored surface.

(Response Order: green then red, or red then green) design. Participants completed a practice block of 10 trials, and then performed 288 trials in one of the unicolor paradigms or 576 trials in the color-segmented paradigm.

In Experiment 2, stimulus duration was varied using a staircase design. Based on pilot data, the starting unicolor stimulus duration was $2000 \mathrm{~ms}$ and the color-segmented stimulus duration was $1000 \mathrm{~ms}$. Each block contained eight trials at a given stimulus duration. If performance was $\geq 87.5 \%$ (7/8), the stimulus duration was decreased in the next block. Otherwise the duration was not long enough to perform the task at criterion, and the stimulus duration increased. The staircase had two stages; in the first the stimulus duration increased or decreased by a step size of $500 \mathrm{~ms}$. Upon a double reversal, the staircase switched to stage two with a $100-\mathrm{ms}$ step size. The staircase ended when stage two produced a double reversal or the $1 \mathrm{~h}$ session was completed. The time required to process both directions correctly was taken as the average between the final two durations at the staircase plateau.

\section{DATA ANALYSIS}

Correct perceptual responses for directions one and two were defined as being those that fell within a range that extended from halfway between the two directions to $45^{\circ}$ away from the real directions (Figure 2). This was to account for variability in participant's responses due to repulsion effects. In order to compare them, correct responses in the color-segmented paradigm were computed the same way as in the unicolor paradigms: the two direction responses were deemed correct or incorrect without regard to whether the directions matched the correct color surface. In essence, this was analyzing performance in the

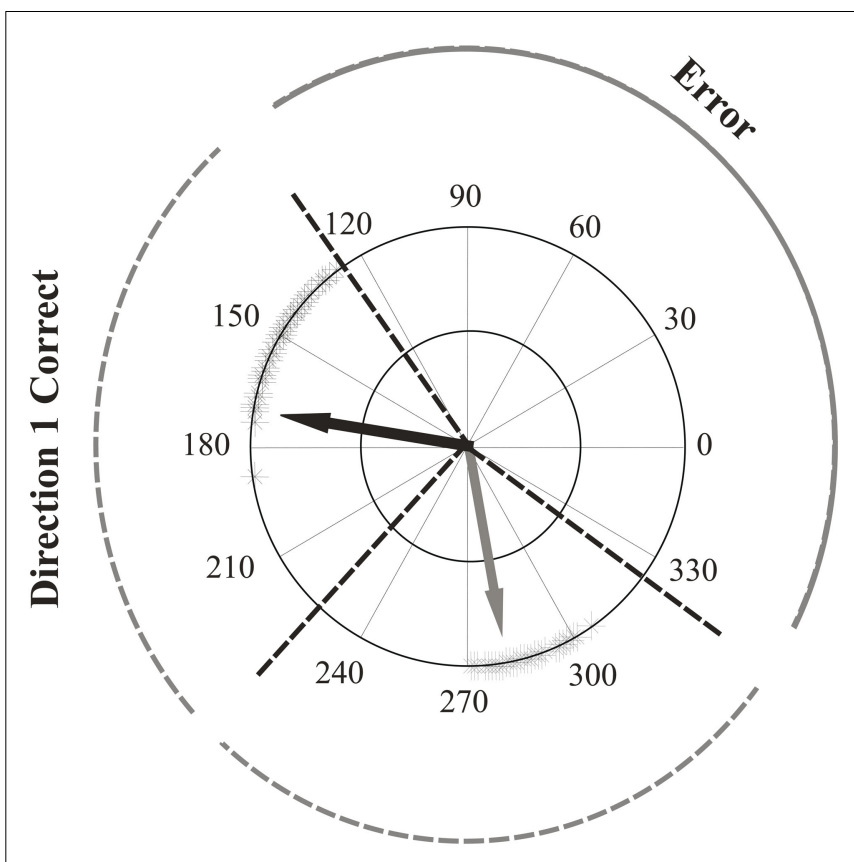

\section{Direction 2 Correct}

FIGURE 2 | Response range of an example participant with correct and error ranges indicated. Shown are all the both-correct responses one participant made to surfaces that were moving at between $170-190^{\circ}$ and $260-280^{\circ}$. Note that the responses are repulsed away from each other and from the real directions. Overlaid are the ranges used to determine the both-correct, one-wrong and both-wrong rates for surfaces moving at $170^{\circ}$ and $280^{\circ}$. Correct ranges were defined as halfway between the two directions to $\pm 45^{\circ}$. One-wrong rates then were trials in which participants clicked on the response circle within the correct range for either direction one or direction two, and made a second response within the error range. Both-wrong rates were based on trials in which participants made both clicks on the response circle within the error range.

color-segmented paradigm as if the color of the surfaces were irrelevant. For all paradigms, only trials in which both directions were correct were included in the direction repulsion analysis. The perceived angle was the difference between the two response directions. Direction repulsion was computed as the difference between the perceived angle and the actual angle difference between the two directions of motion. Positive values indicated direction repulsion.

In Experiment 1, performance was also calculated, measuring the rate at which participants: responded correctly to both surfaces (both-correct), responded correctly to one surface (onewrong), and were unable to respond correctly to either surface (both-wrong). We also calculated total error rate which included all trials in which participants got either one response or both responses incorrect (total error rate $=1$ - both-correct rate).

Means were calculated for each variable: direction repulsion, both-correct, one-wrong, both-wrong, total error, and stimulus duration. Independent $t$-tests were performed for direction repulsion and stimulus duration analyses comparing means in the unicolor versus the color-segmented paradigms. As the error rates may violate the normality assumptions underlying the $t$-test, we 
performed Wilcoxon rank-sum tests on both-correct, one-wrong, both-wrong, and total errors between the paradigms.

\section{RESULTS}

\section{EXPERIMENT 1}

We hypothesized that direction repulsion would be attenuated with the addition of a different color to each of the surfaces as this would further segment the surfaces making them more distinct from one another. We expected no difference between the two unicolor paradigms.

It is important to remove errors caused by guessing from our repulsion analysis, because guesses, as outliers, would be independent of the repulsion effect but would skew the distribution means. Therefore, correct ranges were set a priori based on previous literature (Marshak and Sekuler, 1979; Mather and Moulden, 1980; Hiris and Blake, 1996; Braddick et al., 2002) which showed peak single surface repulsions of $\sim 20^{\circ}$ with an angular difference between the two real directions of $22.5^{\circ}$. In our range of $70-110^{\circ}$ angular differences, those studies found a mean repulsion of $3-$ $9^{\circ}$. In addition, if a participant did not fully process one of the directions of motion, they were still required to respond, thus forcing guesses. As we presented directions $\pm 2^{\circ}, 6^{\circ}, 10^{\circ}$ from each of the four cardinal directions, guesses should therefore be clustered around the cardinal directions. We used a cutoff of $+45^{\circ}$ (half the distance between the correct direction and the closest cardinal direction) which encompasses the mean repulsions seen in prior research and excludes guesses at the remaining cardinal directions. Figure 2 depicts the correct and error ranges for an example pair of directions. To determine if the cutoff was appropriate, we plotted the distribution of responses for an example participant from each of the unicolor and color-segmented conditions (Figure 3 ). The responses show multiple distinct distributions. The distribution around the actual direction of motion (normalized to $0^{\circ}$ ) falls within the $45^{\circ}$ cutoff and is shifted to the right, consistent with direction repulsion. Trials outside this range, considered error trials in our analysis, show clustering around repulsion magnitudes of $90^{\circ}$ and $180^{\circ}$, consistent with guessing around the remaining cardinal directions.
The motion processing system is generally considered to be color-blind (Maunsell and Van Essen, 1983a,b; Shipp and Zeki, 1985; Zeki et al., 1991), however a few recent studies have suggested that color and motion processing may be linked (Croner and Albright, 1997, 1999; Tchernikov and Fallah, 2010). Therefore, we first tested whether the addition of color itself affected direction processing by comparing the unicolor: white and unicolor: red or green paradigms. We found no significant differences in any of our measures: Direction Repulsion $[t(10)=0.84$, $p=0.42]$, Both-Correct rates $\left(W_{\mathrm{s}}=31.00, z=-1.28, p=0.24\right)$, One-Wrong rates $\left(W_{\mathrm{s}}=30.00, z=-1.44, p=0.18\right)$, Both-Wrong rates $\left(W_{\mathrm{s}}=33.5, z=-0.89, p=0.39\right)$, and Total Error rates $\left(W_{\mathrm{s}}=31.00, z=-1.28, p=0.24\right)$. We collapsed the two unicolor paradigms for the remaining analyses.

We next compared the color-segmented paradigm to the combined unicolor paradigms. On correct trials, mean direction repulsion in the unicolor paradigm $\left(7.32 \pm 1.45^{\circ}\right)$ did not differ significantly from the color-segmented paradigm $\left[7.45 \pm 3.50^{\circ}\right.$, $t(16)=-0.04, p=0.97-$ see Figure 4]. The addition of color segmentation cues did not affect motion perception, specifically the illusory direction repulsion. However, participants' performance, that is their ability to correctly determine both directions, was significantly higher in the presence of color segmentation cues $(93.3 \pm 0.75 \%)$ versus the unicolor condition $\left(80.48 \pm 2.74 \% ; W_{\mathrm{s}}=83.00, z=-2.90, p=0.002\right)$. This is also shown in the total error rate (proportion of trials in which the participant responded incorrectly to either one or both of the directions - see Figure 5). There was a significant decrease $\left(W_{\mathrm{s}}=26.00, z=-2.90, p=0.002\right)$ in the total error rate in the color-segmented condition $(6.67 \pm 0.75 \%)$ compared to the unicolor condition $(19.52 \pm 2.74 \%)$. To determine what was driving the difference in performance, error trials were broken down into two categories: when only one direction was incorrectly determined (One-Wrong) or when both were incorrectly determined (Both-Wrong). There was a significant difference in Both-Wrong error rates $\left(W_{s}=31.00, z=-2.45, p=0.013\right)$ between the unicolor $(1.97 \pm 0.57 \%)$ and the color-segmented $(0.17 \pm 0.06 \%)$ conditions (Figure 5). The Both-Wrong error rates

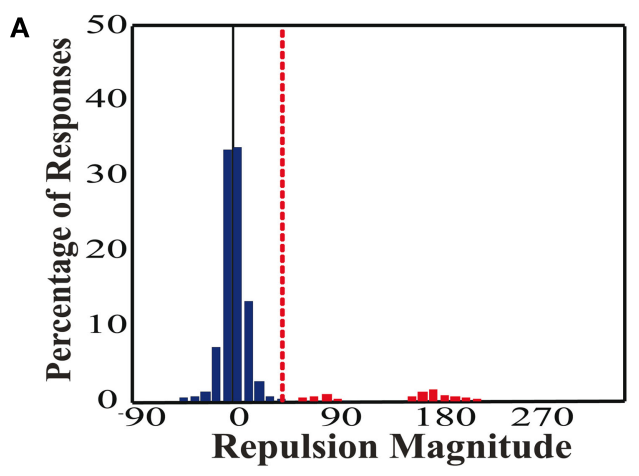

FIGURE 3 | Example distributions of repulsion magnitude. (A) Unicolor, (B) Color-segmented. Responses are plotted for one participant in each paradigm. The real direction of motion was normalized to $0^{\circ}$ repulsion (black vertical line). The $+45^{\circ}$ cutoff is depicted by the red dashed

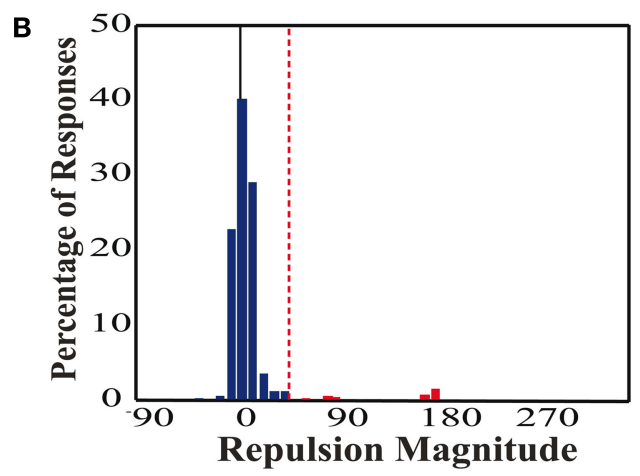

line. Responses outside of this range are indicated in red and were classified as errors. Note the majority of responses fall within the correct range. The errors are distributed around $90^{\circ}$ and $180^{\circ}$, consistent with guessing the remaining cardinal directions. 


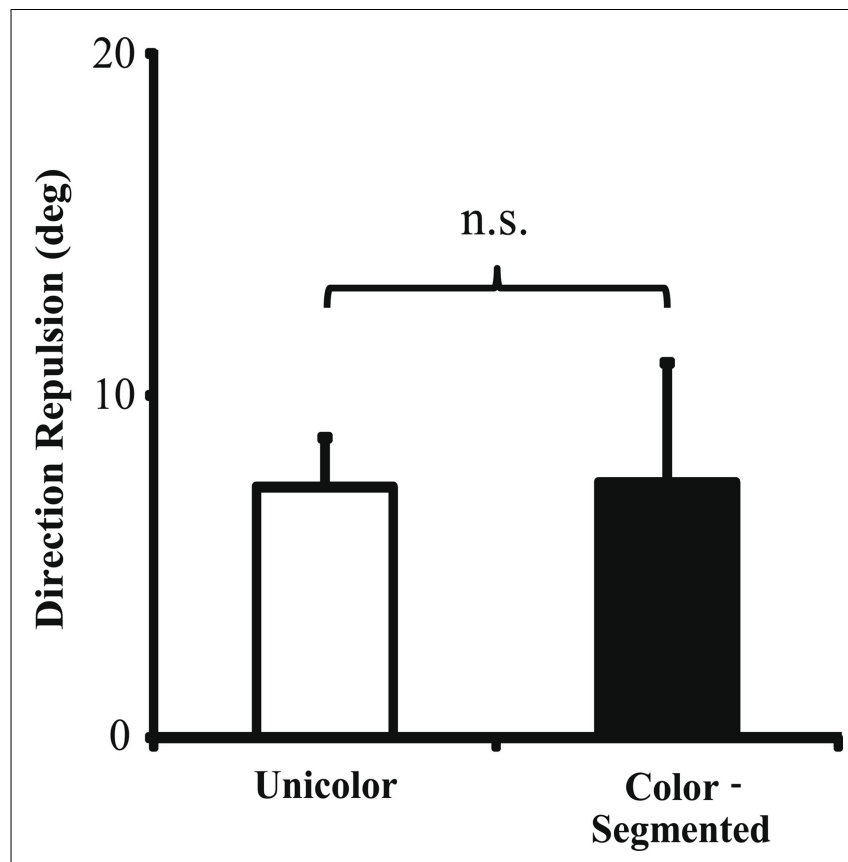

FIGURE 4 | Direction repulsion in Experiment 1. There was no significant change in direction repulsion between the unicolor $\left(7.32 \pm 1.45^{\circ}\right)$ and color-segmented $\left(7.45 \pm 3.50^{\circ}\right)$ paradigms $[t(16)=-0.04, p=0.97]$. Error bars depict SEM.

were under $2 \%$, thus participants were able to process at least one of the directions on nearly every trial (Unicolor: 98.03\%, Color-Segmented: 99.8\%). Note that the 2\% difference in BothWrong error rates between the conditions was a small proportion of the difference in overall performance (Unicolor: $80.48 \%$, ColorSegmented: 93.3\%). Instead, the addition of color segmentation cues improved performance by significantly reducing the OneWrong error rate (Unicolor: $17.55 \pm 2.26 \%$, Color-Segmented: $6.5 \pm 0.75 \% ; W_{\mathrm{s}}=26.00, z=-2.90, p=0.002$; Figure 5). While direction repulsion was not affected by the presence of color segmentation cues, the ability to process not just one but both directions was significantly improved.

\section{EXPERIMENT 2}

In Experiment 1, participants were able to correctly determine the direction of one of the surfaces whether or not color differences were present. The addition of color segmentation cues significantly improved participants' ability to process the second direction of motion, without affecting the direction repulsion illusion. We hypothesized that the addition of color may have speeded processing without affecting perception, even though there was the added task demand of associating direction with color. In Experiment 1, the stimuli were presented for $1000 \mathrm{~ms}$, which was sufficient time to perform the task when the surfaces were segmented by color, but apparently not enough time to process both unicolor surfaces. In Experiment 2, we varied the duration of stimulus presentation to determine how much time was necessary to process both directions with and without color segmentation cues. We predicted that without color segmentation cues, a presentation

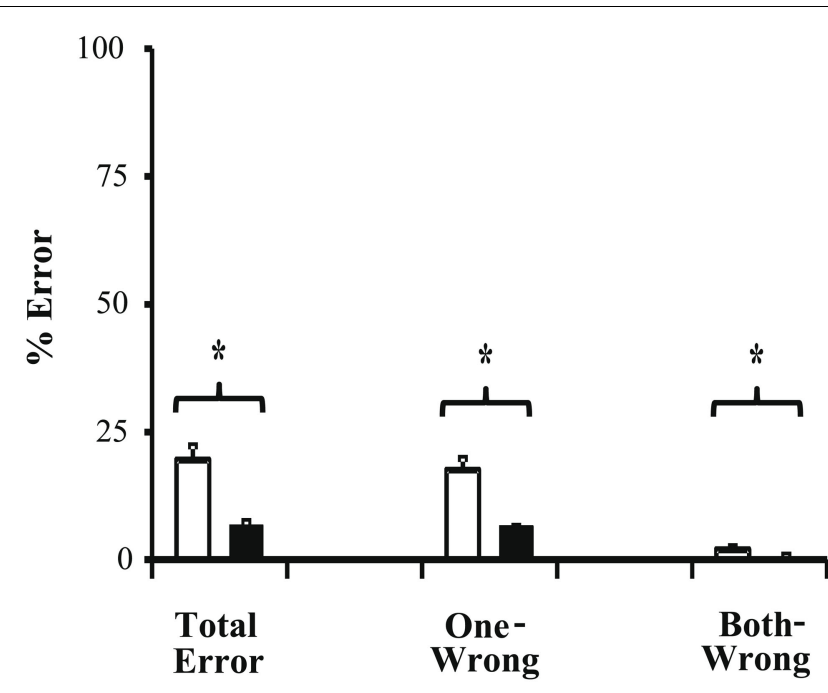

FIGURE 5 | Error rates for Experiment 1. There was a significant decrease in total error rate $\left(W_{s}=26.00, z=-2.90, p=0.002\right)$ in the color-segmented condition (black bars; $6.67 \pm 0.75 \%$ ) compared to the unicolor condition (white bars) $19.52 \pm 2.74 \%$ ). One-wrong errors accounted for the majority of the total error rate and had a corresponding significant decrease $\left(W_{s}=26.00, z=-2.90, p=0.002\right)$ in the color-segmented condition $(6.51 \pm 0.75 \%)$ compared to the unicolor condition $(17.55 \pm 2.26 \%)$. The both-wrong rate, while showing a significant difference $\left(W_{\mathrm{s}}=31.00\right.$, $z=-2.45, p=0.013)$ between the color-segmented $(0.17 \pm 0.06 \%)$ and unicolor $(1.97 \pm 0.57 \%)$, accounted for only a very small portion of the total error trials. Errors bars are SEM.

time of greater than $1000 \mathrm{~ms}$ would be necessary to process both directions of motion.

Consistent with Experiment 1, there was no significant difference in direction repulsion between the unicolor $\left(14.02 \pm 1.39^{\circ}\right)$ and color-segmented $\left(13.79 \pm 1.54^{\circ}\right)$ conditions $[t(22)=0.12$, $p=0.91-$ see Figure 6A]. We performed an omnibus direction repulsion analysis using a 2 (Experiment 1 versus 2$) \times 2$ (Segmentation: Unicolor versus Color-segmented) ANOVA. There was a significant main effect of Experiment $(p=0.001)$, but no main effect of Segmentation $(p=0.82)$ nor a significant interaction $(p=0.87)$. It is also possible that due to the between-subjects design, the repulsion magnitude difference is based upon group differences between the participants in Experiments 1 and 2. However, it is unlikely that random assignment of 42 participants would result in such a large and significant difference. The repulsion magnitude difference is more likely due to differences in the two experimental paradigms. In Experiment 1, the timing is set and known, whereas in Experiment 2, it is variable. We can only speculate that this may produce different levels of alertness and/or arousal resulting in the magnitude differences. It is important to note that while there is a difference in direction repulsion magnitude between the two experiments, the addition of color segmentation, within each experiment, did not affect direction repulsion.

As expected, participants required less than $1000 \mathrm{~ms}$ to process both directions when the surfaces were segmented by color $(841.7 \pm 150.5 \mathrm{~ms})$. In the unicolor condition, participants on 


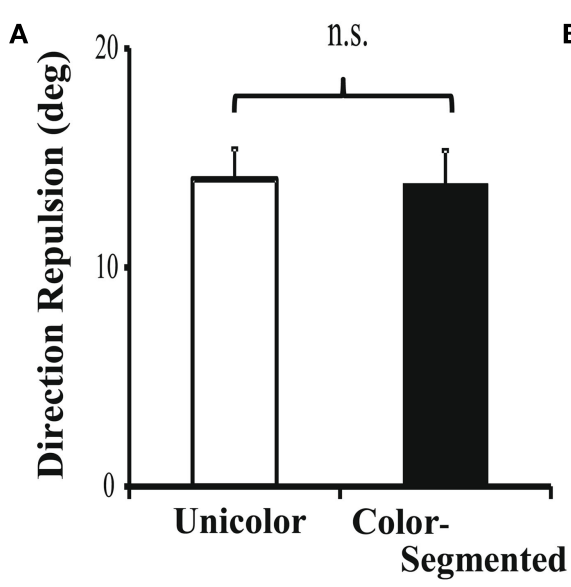

FIGURE 6 | Direction repulsion and stimulus duration results for Experiment 2. (A) As in Experiment 1, there was no significant modulation of direction repulsion with the addition of color $\left(13.79 \pm 1.54^{\circ}\right)$ when compared to the unicolor $\left(14.02 \pm 1.39^{\circ}\right)$ condition $[t(22)=0.12$,

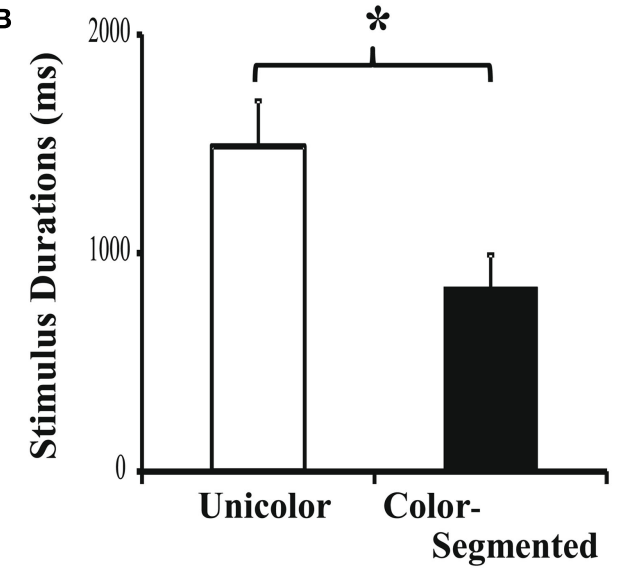

$p=0.91]$. (B) Participants required significantly less time in the color-segmented paradigm $(841.7 \pm 150.5 \mathrm{~ms})$ than in the unicolor paradigm ( $1487.5 \pm 208.5 \mathrm{~ms}$ ) to correctly process both directions $[t(22)=2.51, p=0.02]$. Error bars are SEM. average required $1488 \mathrm{~ms}$ to process both directions of motion $(1487.5 \pm 208.5 \mathrm{~ms})$. The presentation time required in the unicolor condition was significantly longer than in the colorsegmented condition $[t(22)=2.51, p=0.02$ - see Figure 6B]. This difference in timing supports the results of Experiment 1. Color segmentation enabled processing both directions of motion within $1000 \mathrm{~ms}$ (93\% performance), but in the unicolor condition, participants were not always able to process the second surface's direction ( $80 \%$ performance). Thus, the addition of color segmentation cues, providing an additional feature by which to select a surface, significantly speeded processing in the motion discrimination task without affecting conscious perception of the direction repulsion illusion.

\section{DISCUSSION}

In the direction repulsion illusion, previous work has shown that conscious misperception of motion direction can be altered through the use of bottom-up segmentation cues, which are thought to reduce the effect of mutual inhibition between the superimposed objects. When the objects were distinguished from each other by differences in speed (Marshak and Sekuler, 1979; Curran and Benton, 2003) or spatial frequency (Kim and Wilson, 1996), direction repulsion was reduced resulting in a more realistic conscious experience. Note that speed and spatial frequency are co-processed with direction in motion-sensitive visual areas, such as area MT, in the dorsal visual processing stream (for review, see Born and Bradley, 2005). Evidence suggests that motion processing is segregated along different speed (Edwards et al., 1998) or spatial frequency channels (Kim and Wilson, 1993). Thus, direction repulsion could be attenuated by segregating the objects by different speed (Curran and Benton, 2003) or spatial frequency channels (Kim and Wilson, 1996). As superimposed transparent surfaces are automatically perceived as being at different apparent depths, additionally segmenting the surfaces by stereoscopic depth does not attenuate direction repulsion (Hiris and Blake, 1996). We hypothesized that distinguishing two superimposed objects by a feature processed outside of the dorsal stream, providing both bottom-up segmentation cues and an additional top-down task demand, should also attenuate direction repulsion. Such a finding would be consistent with attention to an object strengthening the conscious representation of all the features of that object. In contrast, our findings show that conscious perception of motion direction is unaffected: direction repulsion was no different when the objects were additionally segmented by color versus when they were the same color. This result suggests that color cues had no effect on motion processing: computing direction was blind to the color of the moving object. While illusory perception of the direction repulsion was not affected, we did find that participants' ability to process both objects' directions of motion in a set period of time was improved with the addition of color. When the surfaces were only segmented by direction (unicolor condition), one of the directions of motion did not always reach conscious awareness. But color segmentation brought both directions of motion into conscious awareness. We hypothesized that color sped processing in the task, similar to how attentional facilitation speeds reaction times. Speeded processing would allow the direction computation to complete and enter conscious awareness, without affecting the perceived direction. In Experiment 2, we varied the presentation duration to test this hypothesis and determine how much time was necessary to process both objects' directions with and without color cues. Color segmentation did indeed speed visual processing, resulting in participants requiring less time (color-segmented: $\sim 840 \mathrm{~ms}$; unicolor: $\sim 1490 \mathrm{~ms}$ ) to fully process the directions of motion of both objects. These timings were consistent with the results of Experiment 1 that used a set $1000 \mathrm{~ms}$ stimulus duration. Therefore, while determining the global motion direction of colored, coherently moving dots requires a hierarchical object representation, attention to one feature of the object (color) did not modify the conscious percept of other features of the object (direction of motion). However, segmentation by that feature did speed processing of other features, allowing them to enter conscious awareness more quickly. 


\section{SPEEDED PROCESSING AND REACTION TIME STUDIES}

Our results suggest that the representation of an object's features in conscious perception is independent of the speed at which the neural circuitry processes that sensory input. A number of spatial attention studies have focused on detection tasks where performance is at ceiling (e.g., the precueing paradigm, Posner, 1980). The effect of spatial attention is then measured as changes in the speed of response, termed reaction time. As the strength and quality of the sensory input is already high, attention is thought to speed visual processing in these paradigms. Behavioral studies of non-spatial object-based attention using superimposition (e.g., Duncan, 1984; Valdes-Sosa et al., 1998, 2000; Reynolds et al., 2003) have generally measured accuracy of discrimination judgments and thus have not investigated effects on processing speed (but see Tipper, 2001, for a review of negative priming: slower reaction times resulting from distractor inhibition). Our results are consistent with attentional speeding of visual processing, but we also show that it is not limited to spatial attention because the surfaces are superimposed. In fact, we recently performed a reaction time precueing study using superimposed surfaces (Fallah et al., under review). In that study, non-spatial object-based attention modulated response times, supporting the point that speeded visual processing is not limited to spatial attention.

\section{PRE-ATTENTIVE PROCESSING}

We have suggested that color segmentation speeds motion processing due to attentional mechanisms because attention has been shown to speed visual processing (e.g., reaction times). However, it is also possible that color segmentation increased the speed of motion processing through pre-attentive mechanisms. That is, the effects of color segmentation could have been due to feed-forward pre-attentive processing of the motion direction and not been reliant on attentional feedback. This would occur if color and motion are bound prior to or during motion processing. As additional time is required to bind different features together (Bodelon et al., 2007), linking color and motion pre-attentively would need to provide a larger speed advantage than that cost. Due to the magnitude of the benefit seen with color segmentation in this task, it is possible that more than one mechanism is in effect. In the following discussion of the different stages of visual processing wherein color segmentation could potentially speed motion processing, we will highlight which mechanisms rely on pre-attentive or attentive processing.

\section{TIMING MODELS}

This task required top-down and bottom-up attention along with visual processing, working memory and hierarchical object processing. As such, there are a number of stages of processing required to perform the task, but we are only focusing on the stages necessary during the presentation of the stimuli and not the memory retrieval and response stages. We propose two possible models: one based on serial processing and another based on parallel processing. The serial model is based on prior studies that have shown people are impaired at simultaneously processing features on two different, superimposed objects (Neisser and Becklen, 1975; Duncan, 1984; Blaser et al., 2000), and thus may select and process one object before switching and processing the other object. Alternatively, the directions of both objects could be processed in parallel. Figure 7A depicts the necessary stages of processing in the serial model. Participants first need time to separate the dots into two different objects (SG: segmentation time), in order to process the direction of the first object (D1: direction discrimination of object 1 ). Note that processing the direction includes motion processing, decision-making and storage in working memory. The time to complete these two stages is the time needed to completely process the first object ( $\mathrm{T} 1$ : time to process direction 1). Once the first object is processed, participants need to disengage attention from this object and switch their attention to the second object (SW: switch). Then the direction of the second object can be determined (D2). T2 is the time needed to accomplish these two (SW and D2) stages. Completing all of the stages is the time needed to determine the direction of both objects. In the parallel model (Figure 7E), the dots are also initially segmented into two separate objects (SG). Then both directions are processed in parallel (D1 and D2). The parallel direction processing may occur at equal rates or one may complete before the other, consistent with our one-correct rates. Whether the process is serial or parallel, color segmentation may increase the speed of processing at one or more of these stages. We propose three models wherein different stages of processing may be speeded by the addition of color cues. We also review possible anatomical underpinnings of each.

\section{Segmentation}

The first model is based on color speeding segmentation (SG) of the dots into two superimposed objects, resulting in a decrease in the total time required to perform the task. This could occur through pre-attentive processing and affect both the serial (Figure 7B) and parallel (Figure 7F) mechanisms. In this paradigm, segmentation is mainly dependent on the Gestalt principle of common fate: items that move together are grouped together (e.g., Blake and Lee, 2005). Two fields of dots that are superimposed but not moving appear as a single surface, whether or not they differ in color. It is the motion of the dots that segments them into two superimposed objects. It is at this stage that the two superimposed objects, but not the directions of motion, enter conscious awareness. The addition of color cues increases the strength of segmentation between the two objects. It may be that in addition to increasing the segmentation strength, color cues also speed the segmentation process by grouping the dots into two objects more efficiently. Color and motion are processed separately, starting with different photoreceptors in the retina and continuing through separate functional areas in cortex (Ungerleider and Mishkin, 1982; Goodale and Milner, 1992; Milner and Goodale, 1993). In cortical visual processing the ventral stream is sensitive to color, whereas the dorsal stream is sensitive to motion. Color could affect motion segmentation through the anatomical links between area V4, which represents perceived color, and area MT, which processes motion (Ungerleider and Haxby, 1994). As color is processed faster than motion (Moutoussis and Zeki, 1997), it therefore would be available to aid in grouping the dots and segmenting the objects by motion. Such color-motion interaction would occur during early pre-attentive visual processing. While prior research has suggested that area MT may use color 

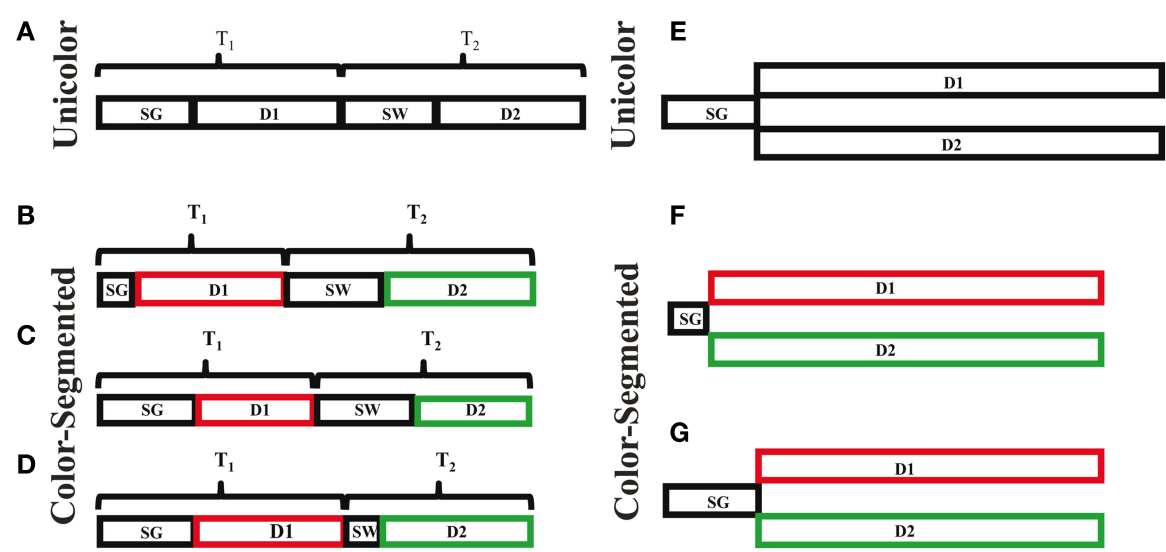

FIGURE 7 | Task processing and timing models. Serial models are depicted in (A-D). (A) Shows the time components involved in processing the directions of both surfaces. T1, the time to process the direction of one surface, is divided into the time needed to segment the surfaces (SG), and the time to discriminate the direction (D1).T2, the time to process the direction of the other surface, is divided into the time needed to disengage attention from surface one and instead attend to the other surface, i.e., switch (SW), and the time required to distinguish the direction of surface two (D2). (B) Faster segmentation hypothesis; the time needed to segment (SG) the surfaces decreases with the addition of a color difference, thus decreasing the amount of time to process surface one (T1), and the total time needed to

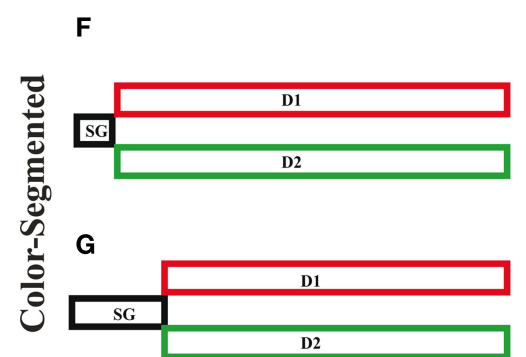

perform the task. (C) Faster motion processing hypothesis; the addition of color reduces the time needed to process the direction of each surface. Again, the total time needed to perform the task decreases. (D) Faster attentional switch hypothesis; color reduces the amount of time required to disengage attention from surface 1 and switch to processing surface 2 (SW), thus reducing the time needed to process the second surface (T2), and the total time needed to perform the task. Parallel models are depicted in (E-G). This would eliminate the need to switch attention between objects, leaving decreased segmentation time (F), and faster motion processing (G), as possible mechanisms through which decreased processing time in the color-segmented paradigm could occur. to segment moving dots (Croner and Albright, 1997; Born and Bradley, 2005), this study suggests that color may also speed the segmentation by motion process. Since increased discriminability of a texture-defined object only speeds segmentation time by up to $25 \mathrm{~ms}$ (Caputo and Casco, 1999), it is not likely that color affecting SG alone can account for the total difference in processing time.

\section{Sensory processing}

The second model is based on color speeding motion processing, resulting in a decrease in both D1 and D2. This would affect both the serial (Figure 7C) and parallel (Figure 7G) mechanisms. Historically motion processing was thought to be color-blind (Maunsell and Van Essen, 1983a,b; Shipp and Zeki, 1985; Zeki et al., 1991), especially since the dorsal stream that processes motion only receives magnocellular (rod) input and not parvocellular (cone) input. More recently, evidence is accumulating that color can affect motion processing, possibly through cross-talk connections between areas V4 and MT (Ungerleider and Desimone, 1986). For example, Croner and Albright (1997, 1999) found that direction discrimination was enhanced when distractors were distinguished by color. More recently, Tchernikov and Fallah (2010) found that color modulated the speed of smooth pursuit eye movements, thought to be dependent on motion processing in area MT (Lisberger and Ferrera, 1997; Recanzone and Wurtz, 1999). Thus color processing within the ventral stream has both anatomical and functional connectivity with motion processing in the dorsal stream. The outstanding question is how do those connections speed processing without affecting the perception of motion?

In order to process motion, MT first needs to associate the identity of each dot across two frames (aliasing - Snowden and
Braddick, 1990), and then use Gestalt rules of common fate to group dots with common motion directions into the two global objects. The common color of dots within the same object may speed processing by reducing the aliasing options; each dot has half as many possible matches across frames of motion in the color-segmented than in the unicolor condition. This could either occur through pre-attentive processing if color segregates motion input early in the visual processing stream, by top-down attentional selection through color filtering (Croner and Albright, 1997, 1999), or by bottom-up attention as surfaces provide an advantage over lower-level features in visual search (He and Nakayama, 1992). Concurrent direction judgments of superimposed surfaces are based on the global motion representations of each surface (Braddick et al., 2002). We suggest that it is the global motion processing of each surface that is affected by color segmentation. Then, once each surface's direction is determined, mutual inhibition between the populations of neurons representing each direction shifts the perceived directions away from each other. Thus, time to process may be affected by color segmentation in this task, without affecting the conscious misperception of the directions of the objects.

Alternatively, it may be possible to speed the decision-making process. Direction judgments have been shown to be based on area MT processing motion information (Albright, 1984; Mikami et al., 1986a,b; Newsome and Pare, 1988; Salzman et al., 1992) and passing the information along to area LIP which accumulates the evidence to reach a decision threshold (accumulator model: Shadlen and Newsome, 1996, 2001; Huk and Shadlen, 2005; Palmer et al., 2005). LIP also receives color information directly from area V4, an intermediate stage of feature processing in the ventral visual stream (Ungerleider and Haxby, 1994). In this model, area MT contains 
direction processing circuitry, including that of mutual inhibition which produces direction repulsion, and passes the two misperceived directions to LIP which accumulates this information over time. In the unicolor condition, segmentation occurs solely on the basis of motion direction and thus the direction of one surface interferes with the accumulation of direction information for the other surface. This leads to a "noisy walk" toward threshold (e.g., Palmer et al., 2005). When the motion information is separated by color, focusing on a single color reduces the noise produced by the other surface's direction which increases the slope of accumulation, resulting in a faster approach to the decision threshold. Note that this would occur after mutual inhibition in area MT produces the misperceived directions. The accumulator model can account for differences in reaction time based on the strength of the motion stimulus (motion coherence) and for speed-accuracy tradeoffs (Palmer et al., 2005). We hypothesize that attention, using color segmentation, gates direction information after motion processing which leads to speeded decision-making (accumulator model) without affecting conscious perception (direction repulsion). While our experiments cannot determine whether motion processing or decision-making occur faster, future studies can test these hypotheses by performing neuronal recordings in areas MT and LIP.

\section{Attentional switching}

The third model is based on color differences producing faster attentional switching between objects; seen as a decrease in SW and thus T2 time. This model only affects the serial mechanism (Figure 7D), as there is no attentional switching in the parallel model. Switching attention between objects at a given location has best been studied in the attentional blink paradigm. In attentional blink, it has been shown that being able to switch one's attention between serially presented objects is limited when the objects appear within $\sim 100-500$ ms of each other (Shapiro et al., 2009). Color segmentation provides an additional feature by which to select a surface, which could produce an advantage of up to a few hundred milliseconds.

Attentional control is thought to be mediated by distinct ventral and dorsal attention networks (Corbetta and Shulman, 2002; Shulman et al., 2002; Sridharan et al., 2007). The dorsal attention network is involved in top-down control of attention to locations, objects, and features (Corbetta et al., 1993; Nobre et al., 1997; Corbetta, 1998; Shulman et al., 1999; Yantis and Serences, 2003; Serences et al., 2004; Kelley et al., 2008; Ozaki, 2011). The dorsal attention network has also been shown to be driven by bottom-up attentional cues relating to motion but not by color cues (Shulman et al., 2002; d'Avossa et al., 2003), whereas color saliency activates occipitotemporal regions instead (Kincade et al., 2005). While attentional switching activates both attention networks (Corbetta and Shulman, 2002; Serences et al., 2004), it has been suggested that attentional switching is in fact facilitated by the ventral attention network acting as a "circuit breaker" (Marois et al., 2000; Corbetta and Shulman, 2002; Shulman et al., 2002, 2007; Chambers et al., 2004) whose function is to interrupt an ongoing cognitive task to reorient attention to different behaviorally relevant sensory information (Serences et al., 2005) even at the same spatial location (Greenberg et al., 2010). Therefore, color segmentation would aid in disengaging from one surface and reorienting to the other surface, speeding the attentional switch. In this model, the ventral attention network affects the speed of visual processing, whereas the dorsal attention network is instead linked to conscious perception as it likely mediates attenuation of direction repulsion due to increased segmentation from bottom-up motion features such as speed and spatial frequency.

\section{CONSCIOUSNESS}

Pre-attentive processing could subserve color effects on the segmentation and direction discrimination stages. Attentional mechanisms could underlie color effects on the direction discrimination, decision-making, and attentional switching stages. Based on the magnitude of the color segmentation effect, it is likely more than one stage is affected. These potential attentional mechanisms add to the growing body of evidence that, under certain circumstances, attention and consciousness can be dissociated (Braun and Sagi, 1990; Braun and Julesz, 1998; Kentridge et al., 1999a,b, 2004; Tsushima et al., 2006, 2008; van Boxtel et al., 2010a for a full review). For example, in blindsight, attention can be directed to a stimulus even though the stimulus is not consciously perceived (Kentridge et al., 1999a,b, 2004). In fact, an unseen distractor in the blind field inhibits saccades to consciously perceived targets in the intact visual field (Rafal et al., 1990) similar to a visible distractor in normal participants, i.e., the oculomotor distractor effect (Walker et al., 1995, 1997). As another example, Tsushima et al. (2006, 2008) showed that subthreshold motion coherence (consciously invisible direction) was more distracting in an RSVP task than was suprathreshold motion coherence. Those studies have used stimuli that do not reach conscious awareness to produce a dissociation between attention and consciousness. In the current study, color segmentation did not alter conscious perception of direction, suggesting that in this case processing speed and conscious perception are somehow dissociated even when the stimuli do reach conscious awareness. With or without color segmentation, participants were consciously aware of one of the directions on nearly every trial. Furthermore, with increased presentation time ( $\sim 1500 \mathrm{~ms})$ of the two surfaces, participants were aware of both directions of motion even when they were the same color (Experiment 2, unicolor condition). Thus, color segmentation only sped the entry of motion information into awareness without altering the illusory percept, even though the task required attending to both the color and direction of each surface. This may be due to pre-attentive bottom-up mechanisms, attentional mechanisms, or a combination of the two.

\section{CONCLUSION}

We find that adding color segmentation cues to superimposed objects speeds motion processing, without affecting the misperception of their directions in the direction repulsion illusion. This is in contrast to features within the dorsal stream, specifically speed and spatial frequency, which do affect conscious perception of motion direction, as measured by a reduction in the illusory repulsion. It remains unknown whether those dorsal stream features also speed motion processing or just affect motion perception. Color segmentation affects the speed but not the quality of the direction computation. Speed and spatial frequency affect the 
quality of the direction computation (and may or may not affect the speed of processing). So for color segmentation there is a dissociation between speed of processing, i.e., the time required to reach conscious awareness, and the conscious percept in that awareness. We propose four stages at which color segmentation may speed processing: segmentation, switching, direction discrimination, and decision-making. The dissociation seen between color segmentation and the conscious perception of the direction repulsion illusion is likely due to color and motion being processed separately by the dorsal and ventral visual streams, whereas the

\section{REFERENCES}

Albright, T. D. (1984). Direction and orientation selectivity of neurons in visual area MT of the macaque. J. Neurophysiol. 52, 1106-1130.

Anstis, S., Verstraten, F. A. J., and Mather, G. (1998). The motion aftereffect. Trends Cogn. Sci. (Regul. Ed.) 2, 111-117.

Azzopardi, P., and Cowey, A. (1997). Is blindsight like normal, nearthreshold vision? Proc. Natl. Acad. Sci. U.S.A. 94, 14190-14194.

Azzopardi, P., and Cowey, A. (1998). Blindsight and visual awareness. Conscious. Cogn.7, 292-311.

Bahrami, B. (2003). Object property encoding and change blindness in multiple object tracking. Vis. Cogn. 10, 949-963.

Blake, R., and Lee, S.-H. (2005). The role of temporal structure in human vision. Behav. Cogn. Neurosci. Rev. 4, 21-42.

Blaser, E., Pylyshyn, Z. W., and Holcombe, A. O. (2000). Tracking an object through feature space. Nature 408, 196-199.

Bodelon, C., Fallah, M., and Reynolds, J. H. (2007). Temporal resolution for the perception of features and conjunctions. J. Neurosci. 27, 725-730.

Born, R. T., and Bradley, D. C. (2005). Structure and function of visual area MT. Annu. Rev. Neurosci. 28, 157-189.

Boyer, J. L., Harrison, S., and Ro, T. (2005). Unconscious processing of orientation and color without primary visual cortex. Proc. Natl. Acad. Sci. U.S.A. 102, 16875-16879.

Boynton, G. M., Demb, J. B., Glover, G. H., and Heeger, D. J. (1999). Neuronal basis of contrast discrimination. Vision Res. 39, 257-269.

Braddick, O. J., Wishart, K. A., and Curran, W. (2002). Directional performance in motion transparency. Vision Res. 42, 1237-1248.

Bradley, D. C., and Andersen, R. A. (1998). Center-surround antagonism based on disparity in primate area MT. J. Neurosci. 18, 7552-7565.

Braun, J., and Julesz, B. (1998). Withdrawing attention at little or no cost: detection and discrimination tasks. Atten. Percept. Psychophys. 60, 1-23.

Braun, J., and Sagi, D. (1990). Vision outside the focus of attention. Atten. Percept. Psychophys. 48, 45-58. H. P. (1987). From detection to identification: response to multiple targets in rapid serial visual presentation. Percept. Psychophys. 42, 105-113.

Caputo, G., and Casco, C. (1999). A visual evoked potential correlate of global figure-ground segmentation. Vision Res. 39, 1597-1610.

Carrasco, M., Penpeci-Talgar, C., and Eckstein, M. (2000). Spatial covert attention increases contrast sensitivity across the CSF: support for signal enhancement. Vision Res. 40, 1203-1215.

Castelo-Branco, M., Kozak, L. R., Formisano, E., Teixeira, J., Xavier, J., and Goebel, R. (2009). Type of featural attention differentially modulates $\mathrm{hMT}^{+}$responses to illusory motion aftereffects. J. Neurophysiol. 102, 3016-3025.

Chambers, C. D., Mattingley, J. B., Payne, J. M., and Stokes, M. G. (2004). Fast and slow parietal pathways mediate spatial attention. Nat. Neurosci. 7, 217-218.

Corbetta, M. (1998). Frontoparietal cortical networks for directing attention and the eye to visual locations: identical, independent, or overlapping neural systems? Proc. Natl. Acad. Sci. U.S.A. 95, 831-838.

Corbetta, M., Miezin, F. M., Shulman, G. L., and Petersen, S. E. (1993). A PET study of visuospatial attention. J. Neurosci. 13, 1202-1226.

Corbetta, M., and Shulman, G. L. (2002). Control of goal-directed and stimulus-driven attention in the brain. Nat. Rev. Neurosci. 3, 201-215.

Croner, L. J., and Albright, T. D. (1997). Image segmentation enhances discrimination of motion in visual noise. Vision Res. 37, 1415-1427.

Croner, L. J., and Albright, T. D. (1999). Segmentation by color influences responses of motion-sensitive
Broadbent, D. E., and Broadbent, M.

cross-talk between the streams still allows for speeded processing. In summary, we have shown that a consciously perceived feature of an object can speed the processing of other features of the same object without affecting the outcome of their perceptual processing.

\section{ACKNOWLEDGMENTS}

The research was funded by an NSERC Discovery Grant to Mazyar Fallah and an NSERC Canadian Graduate Scholarship to Carolyn J. Perry.

neurons in the cortical middle temporal visual area. J. Neurosci. 19 3935-3951.

Curran, W., and Benton, C. P. (2003). Speed tuning of direction repulsion describes an inverted U-function. Vision Res. 43, 1847-1853.

d'Avossa, G., Shulman, G. L., and Corbetta, M. (2003). Identification of cerebral networks by classification of the shape of BOLD responses. J. Neurophysiol. 90, 360-371.

de Gardelle, V., Kouider, S., and Sackur, J. (2010). An oblique illusion modulated by visibility: non-monotonic sensory integration in orientation processing. J. Vis. 10, 1-9.

de Gardelle, V., Sackur, J., and Kouider, S. (2009). Perceptual illusions in brief visual presentations. Conscious. Cogn. 18, 569-577.

DeAngelis, G. C., and Newsome, W. T. (1999). Organization of disparityselective neurons in macaque area MT. J. Neurosci. 19, 1398-1415.

Dennett, D. C., and Kinsbourne, M. (1992). Time and the observer: the where and when of consciousness in the brain. Behav. Brain Sci. 15 183-201.

Desimone, R., and Duncan, J. (1995). Neural mechanisms of selective visual attention. Annu. Rev. Neurosci. 18, 193-222.

Di Russo, F., Spinelli, D., and Morrone, M. C. (2001). Automatic gain control contrast mechanisms are modulated by attention in humans: evidence from visual evoked potentials. Vision Res. 41, 2435-2347.

Dosher, B. A., and Lu, Z.-L. (2000). Noise exclusion in spatial attention. Psychol. Sci. 11, 139-146.

Driver, J. (2001). A selective review of selective attention research from the past century. Br. J. Psychol. 91, 53-78.

Driver, J., and Mattingley, J. B. (1998). Parietal neglect and visual awareness. Nat. Neurosci. 1, 17-22.

Duncan, J. (1984). Selective attention and the organization of visual information. J. Exp. Psychol. Gen. 113, 501-517.

Edwards, M., Badcock, D. R., and Smith, A. T. (1998). Independent speed-tuned global-motion systems. Vision Res. 38, 1573-1580.

Egeth, H. E., and Yantis, S. (1997). Visual attention: control, representation, and time course. Annu. Rev. Pyschol. 48, 269-297.

Fallah, M., Stoner, G. R., and Reynolds, J. H. (2007). Stimulus-specific competitive selection in macaque extrastriate visual area V4. PNAS 104, 4165-4169.

Goodale, M. A., and Milner, A. D. (1992). Separate pathways for perception and action. Trends. Neurosci. 15, 20-25.

Greenberg, A. S., Esterman, M., Serences, J. T., Wilson, D. E., and Yantis, S. (2010). Control of spatial and feature-based attention in frontoparietal cortex. J. Neurosci. 30, 14330-14339.

He, Z. J., and Nakayama, K. (1992). Surfaces versus features in visual search. Nature 359, 231-233.

Hiris, E., and Blake, R. (1996). Direction repulsion in motion transparency. Vis. Neurosci. 13, 187-197.

Hofstoetter, C., Koch, C., and Kiper, D. C. (2004). Motion-induced blindness does not affect the formation of negative afterimages. Conscious. Cogn. 13, 691-708.

Huk, A. C., and Shadlen, M. N. (2005). Neural activity in macaque parietal cortex reflects temporal integration of visual motion signals during perceptual decision making. J. Neurosci. 25, 10420-10436.

Itti, L., and Koch, C. (2001). Computational modeling of visual attention. Nat. Rev. 2, 194-203.

Jonides, J. (1981). "Voluntary versus automatic control over the mind's eye's movement," in Attention and Performance IX, eds J. B. Long and A. D. Baddeley (Hillsdale: Erlbaum), 187-203.

Kaufman, L., and Rock, I. (1962). The moon illusion. Sci. Am. 207, 120-130.

Kaunitz, L., Fracasso, A., and Melcher, D. (2011). Unseen complex motion is modulated by attention and generates a visible aftereffect. J. Vis. 11, $1-9$. 
Kelley, T. A., Serences, J. T., Giesbrecht, B., and Yantis, S. (2008). Cortical mechanisms for shifting and holding visuospatial attention. Cereb. Cortex 18, 114-125.

Kentridge, R. W., Heywood, C. A., and Weiskrantz, L. (1999a). Attention without awareness in blindsight. Proc. Biol. Sci. 266, 1805-1811.

Kentridge, R. W., Heywood, C. A., and Weiskrantz, L. (1999b). Effects of temporal cueing on residual visual discrimination in blindsight. $\mathrm{Neu}$ ropsychologia 37, 479-483.

Kentridge, R. W., Heywood, C. A., and Weiskrantz, L. (2004). Spatial attention speeds discrimination without awareness in blindsight. Neuropsychologia 42, 831-835.

Kim, J., and Wilson, H. R. (1993). Dependence of plaid motion coherence on component grating directions. Vision Res. 33, 2479-2489.

Kim, J., and Wilson, H. R. (1996). Direction repulsion between components in motion transparency. Vision Res. 36, 1177-1187.

Kincade, J. M., Abrams, R. A., Astafiev, S. V., Shulman, G. L., and Corbetta, M. (2005). An event-related functional resonance imaging study of voluntary and stimulus-driven orienting of attention. J. Neurosci. 25, 4593-4604.

Koch, C., and Ullman, S. (1985). Shifts in selective visual attention: towards the underlying neural circuitry. Hum. Neurobiol. 4, 219-227.

Kolb, F. C., and Braun, J. (1995). Blindsight in normal observers. Nature 28, 336-338.

Kunimoto, C., Miller, J., and Pashler, H. (2001). Confidence and accuracy of near-threshold discrimination responses. Conscious. Cogn. 10, 294-340.

Land, E. H., and McCann, J. J. (1971). Lightness and retinex theory. J. Opt. Soc. Am. 61, 1-11.

Lavie, N. (1995). Perceptual load as a necessary condition for selective attention. J. Exp. Psychol. Hum. Percept. Perform. 21, 451-468.

Lee, D. K., Itti, L., Koch, C., and Braun, J. (1999a). Attention activates winner-take-all competition among visual filters. Nat. Neurosci. 2, 375-381.

Lee, D. K., Koch, C., and Braun, J. (1999b). Attentional capacity is undifferentiated: concurrent discrimination of form, color, and motion. Percept. Psychophys. 61, 1241-1255.

Lisberger, S. G., and Ferrera, V. P. (1997). Vector averaging for smooth pursuit eye movements initiated by two moving targets in monkeys. J. Neurosci. 17, 7490-7502.

Luck, S. J., Chelazzi, L., Hillyard, S. A., and Desimone, R. (1997). Neural mechanisms of spatial attention in areas V1, V2, and V4 of macaque visual cortex. J. Neurophysiol. 77, 24-42.

Mangun, G. R., Buonocore, M. H., Girelli, M., and Jha, A. P. (1998). ERP and AMRI measures of visual selective attention. Hum. Brain Mapp. 6, 383-389.

Marks, L. E., and Stevens, J. C. (1968). The form of the psychophysical function near threshold. Percept. Psychophys. 4, 315-318.

Marois, R., Leung, H.-C., and Gore, J. C. (2000). A stimulus-driven approach to object identity and location processing in the human brain. Neuron 25, 717-728.

Marshak, W., and Sekuler, R. (1979). Mutual repulsion between moving visual targets. Science 205, 1399-1401.

Martinez-Trujillo, J. C., and Treue, S. (2004). Feature-based attention increases the selectivity of population responses in primate visual cortex. Curr. Biol. 14, 744-751.

Mather, G., and Moulden, B. (1980). A simultaneous shift in apparent direction: further evidence for a "distribution-shift" model of direction coding. Q. J. Exp. Psychol. 32, 325-333.

Maunsell, J. H., and Van Essen, D. C. (1983a). Functional properties of neurons in middle temporal visual area of the macaque monkey. I. selectivity for stimulus direction, speed, and orientation. J. Neurophysiol. 49, 1127-1147.

Maunsell, J. H., and Van Essen, D. C. (1983b). Functional properties of neurons in middle temporal visual area of the macaque monkey. II. Binocular interactions and sensitivity to binocular disparity. J. Neurophysiol. 49, 1148-1167.

McAdams, C. J., and Maunsell, J. H. (2000). Attention to both space and feature modulates neuronal responses in macaque area V4. J. Neurophysiol. 83, 1751-1755.

McCollough, C. (1965). Color adaptation of edge-detectors in the human visual system. Science 149, 1115-1116.

Mikami, A., Newsome, W. T., and Wurtz, R. H. (1986a). Motion selectivity in macaque visual cortex. I. Mechanisms of direction and speed selectivity in extrastriate area MT. J. Neurophysiol. 55, 1308-1327.

Mikami,A., Newsome, W. T., and Wurtz, R. H. (1986b). Motion selectivity in macaque visual cortex. II. Spatiotemporal range of directional interactions in MT and V1. J. Neurophysiol. 55, 1328-1339.

Milner, A. D., and Goodale, M. A. (1993). Visual pathways to perception and action. Prog. Brain Res. 95, 317-337.

Moore, T., and Fallah, M. (2001). Control of eye movements and spatial attention. Proc. Natl. Acad. Sci. U.S.A. 98, 1273-1276.

Moore, T., and Fallah, M. (2003). Visuomotor origins of covert spatial attention. Neuron 40, 671-683.

Moore, T., and Fallah, M. (2004) Microstimulation of the frontal eye field and its effects on covert spatial attention. J. Neurophysiol. 91, 152-162.

Morrone, M. C., Denti, V., and Spinelli, D. (2002). Color and luminance contrasts attract independent attention. Curr. Biol. 12, 1134-1137.

Morrone, M. C., Denti, V., and Spinelli, D. (2004). Different attentional resources modulate the gain mechanisms for color and luminance contrast. Vision Res. 44, 1389-1401.

Moutoussis, K., and Zeki, S. (1997). Functional segregation and temporal hierarchy of the visual perceptive systems. Proc. Biol. Sci. 264, 1407-1414.

Mueller, H. J., and Humphreys, G. W. (1991). Luminance increment detection: capacity-limited or not? J. Exp. Psychol. Hum. Percept. Perform. 17, 107-124.

Murd, C., and Bachmann, T. (2011). Spatially localized motion aftereffect disappears faster from awareness when selectively attended to according to its direction. Vision Res. 51, 1157-1162.

Nakayama, K., and Mackeben, M. (1989). Sustained and transient components of focal visual attention. Vision Res. 29, 1631-1647.

Neibur, E., and Koch, C. (1996). Control of selective visual attention: modeling the "where" pathway. Neural Inf. Process. Syst. 8, 802-808.

Neisser, U., and Becklen, R. (1975) Selective looking: attending to visually specified events. Cogn. Psychol. 7, 480-494.

Newsome, W. T., and Pare, E. B. (1988). A selective impairment of motion perception following lesions of the middle temporal visual area (MT). J. Neurosci. 8, 2201-2211.

Nobre, A. C., Sebestyen, G. N., Gitelman, D. R., Mesulam, M. M., Frackowiak, R. S., and Frith, C. D. (1997). Functional localization of the system for visuospatial attention using positron emission tomography. Brain 120, 515-533.

Noe, A., and O’Regan, J. K. (2002) “On the brain-basis of visual consciousness: a sensorimotor account," in Vision and Mind: Selected Readings in the Philosophy of Perception, eds A. Noe and E. Thompson (Cambridge: MIT Press), 567-598.

O'Craven, K. M., Downing, P. E., and Kanwisher, N. (1999). fMRI evidence for objects as the units of attentional selection. Nature 401, 584-587.

Ozaki, T. J. (2011). Frontal-to parietal top-down causal streams along the dorsal attention network exclusively mediate voluntary orienting of attention. PLoS ONE 6, e20079. doi:10.1371/journal.pone.0020079

Palmer, J., Huk, A. C., and Shadlen, M. N. (2005). The effect of stimulus strength on the speed and accuracy of a perceptual decision. J. Vis. 5, 376-404.

Pavani, F., Boscagli, I., Benvenuti, F., Rabuffetti, M., and Farne, A. (1999). Are perception and action affected differently by the Titchener circles illusion? Exp. Brain Res. 127, 95-101.

Posner, M. I. (1980). Orienting of attention. Q. J. Exp. Psychol. 32, 3-25.

Pylyshyn, Z. W. (2004). Some puzzling findings in multiple object tracking (MOT): I. Tracking without keeping track of object identities. Vis. Cogn. 11, 801-822.

Rafal, R., Krantz, J., Smith, J., Cohen, A., and Brennan, C. (1990). Extrageniculate vision in hemianopic humans: saccade inhibition by signals in the blind field. Science 250, 118-121.

Raymond, J. E., Shapiro, K. L., and Arnell, K. M. (1992). Temporary suppression of visual processing in an RSVP task: an attentional blink? J. Exp. Psychol. Hum. Percept. Perform. 18, 849-860.

Recanzone, G. H., and Wurtz, R. H. (1999). Shift in smooth pursuit initiation and MT and MST neuronal activity under different stimulus conditions. J. Neurophysiol. 82, 1710-1727.

Rensink, R. A., O’Regan, J. K., and Clark, J. J. (1997). To see or not to see: the need for attention to perceive changes in scenes. Psychol. Sci. 8, 368-373.

Reynolds, J. H., Alborzian, S., and Stoner, G. R. (2003). Exogenously cued attention triggers competitive selection of surfaces. Vision Res. 43, 59-66.

Reynolds, J. H., and Desimone, R. (2003). Interacting roles of attention and visual salience in V4. Neuron 37, 853-863. 
Reynolds, J. H., and Fallah, M. (2004). "The role of competitive circuits in extrastriate cortex in selecting spatially superimposed stimuli," in Attention and Performance XX, eds N. Kanwisher and J. Duncan (New York: Oxford University Press), 363-380.

Reynolds, J. H., Pasternak, T., and Desimone, R. (2000). Attention increases the sensitivity of V4 neurons. Neuron 26, 703-714.

Rock, I., Linnett, C. M., Grant, P., and Mack, A. (1992). Perception without attention: results of a new method. Cogn. Psychol. 24, 502-534.

Rodriguez-Sanchez, A. J., Simine, E., and Tsotsos, J. K. (2007). Attention and visual search. Int. J. Neural Syst. 17, 275-288.

Saenz, M., Buracas, G. T., and Boynton, G. M. (2002). Global effects of feature-based attention in human visual cortex. Nat. Neurosci. 5, 631-632.

Salzman, C. D., Murasugi, C. M., Britten, K. H., and Newsome, W. T. (1992). Microstimulation in visual area MT: effects on direction discrimination performance. J. Neurosci. 12, 2331-2355.

Scholl, B. J., and Pylyshyn, Z. W. (1999). Tracking multiple items through occlusion: clues to visual objecthood. Cogn. Psychol. 38, 259-290.

Serences, J. T., Schwarzbach, J., Courtney, S. M., Golay, X., and Yantis, S. (2004). Control of object-based attention in human cortex. Cereb. Cortex 14, 1346-1357.

Serences, J. T., Shomstein, S., Leber, A. B., Golay, X., Egeth, H. E., and Yantis, S. (2005). Coordination of voluntary and stimulusdriven attentional control in human cortex. Psychol. Sci. 16, 114-122.

Shadlen, M. N., and Newsome, W. T. (1996). Motion perception: seeing and deciding. Proc. Natl. Acad. Sci. U.S.A. 93, 628-633.

Shadlen, M. N., and Newsome, W. T. (2001). Neural basis of a perceptual decision in the parietal cortex (area LIP) of the rhesus monkey. J. Neurophysiol. 86, 1916-1936.

Shapiro, K. L., Raymond, J., and Arnell, K. (2009). Attentional blink. Scholarpedia J. 4, 3320.

Shipp, S., and Zeki, S. (1985). Segregation of pathways leading from area V2 to areas V4 and V5 of macaque monkey visual cortex. Nature 315, 322-324.

Shulman, G. L., Astafiev, S. V., McAvoy, M. P., d'Avossa, G., and Corbetta, M. (2007). Right TPJ deactivation during visual search: functional significance and support for a filter hypothesis. Cereb. Cortex 17, 2625-2633.

Shulman, G. L., d'Avossa, G., Tansy, A. P., and Corbetta, M. (2002). Two attentional processes in the parietal lobe. Cereb. Cortex 12, 1124-1131.

Shulman, G. L., Ollinger, J. M., Akbudak, E., Conturo, T. E., Snyder, A. Z., Petersen, S. E., and Corbetta, M. (1999). Areas involved in encoding and applying directional expectations to moving objects. J. Neurosci. 19, 9480-9496.

Snowden, R. J., and Braddick, O. J. (1990). Differences in the processing of short-range apparent motion at small and large displacements. Vision Res. 30, 1211-1222.

Spitzer, H., Desimone, R., and Moran, J. (1988). Increased attention enhances both behavioral and neuronal performance. Science 240, 338-340.

Sridharan, D., Levitin, D. J., Chafe, C. H., Berger, J., and Menon, V. (2007). Neural dynamics of event segmentation in music: converging evidence for dissociable ventral and dorsal networks. Neuron 55, 521-532.

Stoerig, P., and Cowey, A. (1997). Blindsight in man and monkey. Brain 120, 535-559.

Sundberg, K. A., Mitchell, J. F., and Reynolds, J. H. (2009). Spatial attention modulates center-surround interactions in macaque visual area V4. Neuron 61, 952-963.

Suzuki, S., and Grabowecky, M. (2003). Attention during adaptation weakens negative afterimages. J. Exp. Psychol. Hum. Percept. Perform. 29, 793-807.

Tchernikov, I., and Fallah, M. (2010). A color hierarchy for automatic target selection. PLoS ONE 5, e9338. doi:10.1371/journal.pone. 0009338

Thompson, K. G., and Bichot, N. P. (2005). A visual salience map in the primate frontal eye field. Prog. Brain Res. 147, 251-262.

Tipper, S. P. (2001). Does negative priming reflect inhibitory mechanisms? A review and integration of conflicting views. Q. J. Exp. Psychol. 54, 321-343.

Treisman, A. M., and Gelade, G. (1980). A feature-integration theory of attention. Cogn. Psychol. 12, 97-136.

Treue, S., and Martinez-Trujillo, J. C. (1999). Feature-based attention influences motion processing gain in macaque visual cortex. Nature 399 575-579.

Tse, P. U., Whitney, D., Anstis, S. and Cavanagh, P. (2011). Voluntary attention modulates motioninduced mislocalization. J. Vis. 11 $1-6$.

Tsotsos, J. K. (2011). A Computational Perspective on VisualAttention. Cambridge: The MIT Press.

Tsotsos, J. K., Culhane, S. M., Wai, W. Y. K., Lai, Y., Davis, N., and Nuflo, F. (1995). Modeling visual attention via selective tuning. Artif. Intell. 78, 507-545.

Tsuchiya, N., and Braun, J. (2007). Contrast thresholds for component motion with full and poor attention. J. Vis. 7, 1.

Tsushima, Y., Sasaki, Y., and Watanabe, T. (2006). Greater disruption due to failure of inhibitory control on an ambiguous distractor. Science 314 1786-1788.

Tsushima, Y., Seitz, A. R., and Watanabe, T. (2008). Task-irrelevant learning occurs only when the irrelevant feature is weak. Curr. Biol. 18, R516R517.

Ungerleider, L. G., and Desimone, R. (1986). Cortical connections of visual area MT in the macaque. J. Comp. Neurol. 248, 190-222.

Ungerleider, L. G., and Haxby, J. V. (1994). "What" and "where" in the human brain. Curr. Opin. Neurobiol. 4, 157-165.

Ungerleider, L. G., and Mishkin, M. (1982). "Two cortical systems," in Analysis of Visual Behavior, eds D. J. Ingle, M. A. Goodale, and J. W. Mansfield (Cambridge: MIT Press), 549-586.

Valdes-Sosa, M., Cobo, A., and Pinila, T. (1998). Transparent motion and object-based attention. Cognition 66, B13-B23.

Valdes-Sosa, M., Cobo, A., and Pinilla, T. (2000). Attention to object files defined by transparent motion. J. Exp. Psychol. Hum. Percept. Perform. 26, 488-505.

van Boxtel, J. J. A., Tsuchiya, N., and Koch, C. (2010a). Consciousness and Attention: on sufficiency and necessity. Front. Psychol. 1:217. doi:10.3389/fpsyg.2010.00217

van Boxtel, J. J. A., Tsuchiya, N., and Koch, C. (2010b). Opposing effects of attention and consciousness on afterimages. Proc. Natl. Acad. Sci. U.S.A. 107, 8883-8888.

van de Grind, W. A., van Hof, P., van der Smagt, M. J., and Verstraten, F. A. J. (2001). Slow and fast visual motion channels have independent binocular-rivalry stages. Proc.
R. Soc. Lond. B Biol. Sci. 268, 437-443.

Van Essen, D. C., and Gallant, J. L. (1994). Neural mechanisms of form and motion processing in the primate visual system. Neuron 13, $1-10$.

Walker, R., Deubel, H., Schneider, W. X., and Findlay, J. M. (1997). Effect of remote distractors on saccade programming: evidence for an extended fixation zone. J. Neurophysiol. 78, 1108-1119.

Walker, R., Kentridge, R. W., and Findlay, J. M. (1995). Independent contributions of the orienting of attention, fixation offset and bilateral stimulation on human saccadic latencies. Exp. Brain Res. 103, 294-310.

Weiskrantz, L. (1986). Blindsight: A Case Study and Implications. Oxford: Oxford University Press.

Wilimzig, C., Tsuchiya, N., Fahle, M., Einhauser, W., and Koch, C. (2008). Spatial attention increases performance but not subjective confidence in a discrimination task. J. Vis. 8, $1-10$.

Yantis, S., and Serences, J. T. (2003). Cortical mechanisms of space-based and object-based attentional control. Curr. Opin. Neurobiol. 13 187-193.

Zeki, S., Watson, J. D., Lueck, C. J., Friston, K. J., Kennard, C., and Frackowiak, R. S. (1991). A direct demonstration of functional specialization in human visual cortex. J. Neurosci. 11, 641-649.

Conflict of Interest Statement: The authors declare that the research was conducted in the absence of any commercial or financial relationships that could be construed as a potential conflict of interest.

Received: 15 October 2011; accepted: 13 March 2012; published online: 29 March 2012.

Citation: Perry $C J$ and Fallah $M$ (2012) Color improves speed of processing but not perception in a motion illusion. Front. Psychology 3:92. doi: 10.3389/fpsyg.2012.00092

This article was submitted to Frontiers in Consciousness Research, a specialty of Frontiers in Psychology.

Copyright (C) 2012 Perry and Fallah. This is an open-access article distributed under the terms of the Creative Commons Attribution Non Commercial License, which permits non-commercial use, distribution, and reproduction in other forums, provided the original authors and source are credited. 